\title{
Introduction to QCA, IVUS and OCT in interventional cardiology
}

\author{
Johan H. C. Reiber
}

Received: 10 January 2011 / Accepted: 13 January 2011/Published online: 20 February 2011

(C) The Author(s) 2011. This article is published with open access at Springerlink.com

It is with great pleasure and honor for me to introduce this topical issue on QCA, IVUS and OCT. QCA has come a long way, from the early 1980s with the angiograms being acquired on $35 \mathrm{~mm}$ cinefilm and requiring very expensive cinefilm projectors with optimal zooming for the quantitative analysis [1], to modern complete digital imaging with the images acquired at resolutions of $512^{2}$ or $1,024^{2}$ pixels, and with the image data widely available throughout the hospital by means of cardiovascular PACS systems. Major differences were of course that on cinefilm the coronary arteries were displayed as bright arteries on a darker background, and there was always an associated pincushion distortion caused by the concave input screen of the image intensifier. With the digital systems the arteries are now displayed as dark vessels on a bright background and the modern flat panel X-ray detectors are free from geometric distortions. Although there have been many years of debate about the resolution of cinefilm versus digital, the higher contrast resolution of the digital approach has compensated much of the higher spatial resolution of the $35 \mathrm{~mm}$ cinefilm, and thus digital has been completly accepted. Also, extensive validation

J. H. C. Reiber ( $₫)$

Division of Image Processing (LKEB), Department of Radiology, Leiden University Medical Center, Leiden, The Netherlands

e-mail: J.H.C.Reiber@lumc.nl studies have not proven major differences in accuracy and precision between cinefilm and digital: the variability in the analysis is for both in the order of

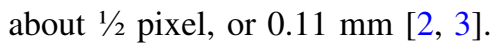

For many years, quantitative coronary arteriography (QCA) has been used in clinical research in the hospitals and in core laboratories to assess regression and progression of coronary obstructions in pharmacological interventions, to assess the efficacy of coronary interventions after the introduction of PTCA and stenting by bare-metal (BMS), drug-eluting (DES) and presently biodegradable stents, and of course for vessel sizing. In all these cases, the analyses were done on straight vessels. New developments have been directed at bifurcation stenting and the associated QCA, and on 3D QCA and registration with IVUS/ OCT. These new issues are elegantly described in the section guest edited by Ricardo A. Costa.

It has been well recognized for many years that despite the wide availability of the angiogram and the QCA, an angiogram is only a lumenogram, and that the disease is in the vessel wall. For proper decision making purposes, the interventionalist must know what the composition is of the plaque. This was made possible with intravascular ultrasound, but with the recent advent of Virtual Histology and the iMAP, even more information has become available, which has revived the field of intravascular ultrasound. In this issue, all the possibilities, limitations and applications of IVUS in interventional cardiology are clearly described in the papers selected by guest 
editor Hector M. Garcia-Garcia. Likewise, optical coherence tomography is now playing a major role in interventional cardiology and great papers have been selected by guest editor Hiram G. Bezerra.

With this special issue on QCA, IVUS and OCT we have assembled timely contributions from leading experts in these fields. All of these developments and their work play a major role in modern interventional cardiology. I wish our readership much pleasure with this special issue.

Open Access This article is distributed under the terms of the Creative Commons Attribution Noncommercial License which permits any noncommercial use, distribution, and reproduction in any medium, provided the original author(s) and source are credited.

\section{References}

1. Reiber JHC, Serruys PW, Kooijman CJ, Wijns W, Slager CJ, Gerbrands JJ, Schuurbiers JCH, den Boer A, Hugenholtz PG (1985) Assessment of short-, medium-, and long-term variations in arterial dimensions from computer-assisted quantitation of coronary cineangiograms. Circulation 71:280-288

2. Reiber JHC, van der Zwet PM, Koning G, von Land CD, van Meurs B, Gerbrands JJ, Buis B, van Voorthuisen AE (1993) Accuracy and precision of quantitative digital coronary arteriography: observer-, short-, and medium-term variabilities. Cathet Cardiovasc Diagn 28(3):187-198

3. Reiber JHC, Tuinenburg JC, Koning G, Jansen JP, Rares A, Lansky AJ, Goedhart B (2009) Quantitative coronary arteriography. In: Oudkerk M, Reiser MF (eds) Coronary radiology, 2nd revised edn [Series: medical radiology, sub series: diagnostic imaging, Baert AL, Knauth M, Sartor K (eds)] , Springer, Heidelberg, pp 41-65 